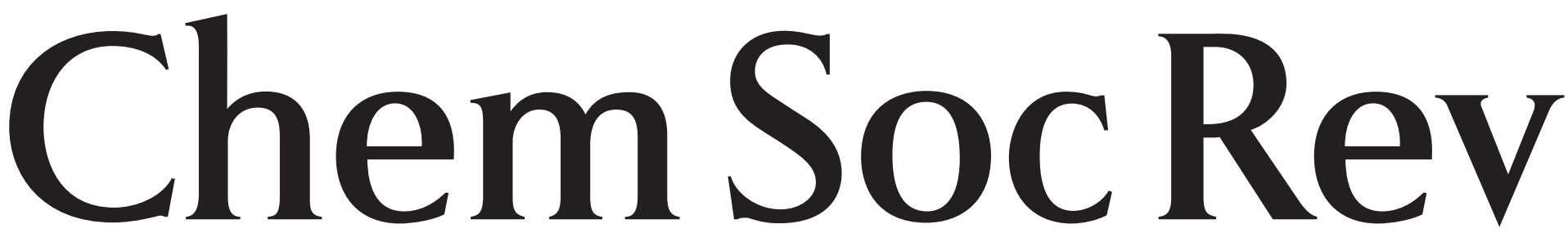

Chemical Society Reviews

44
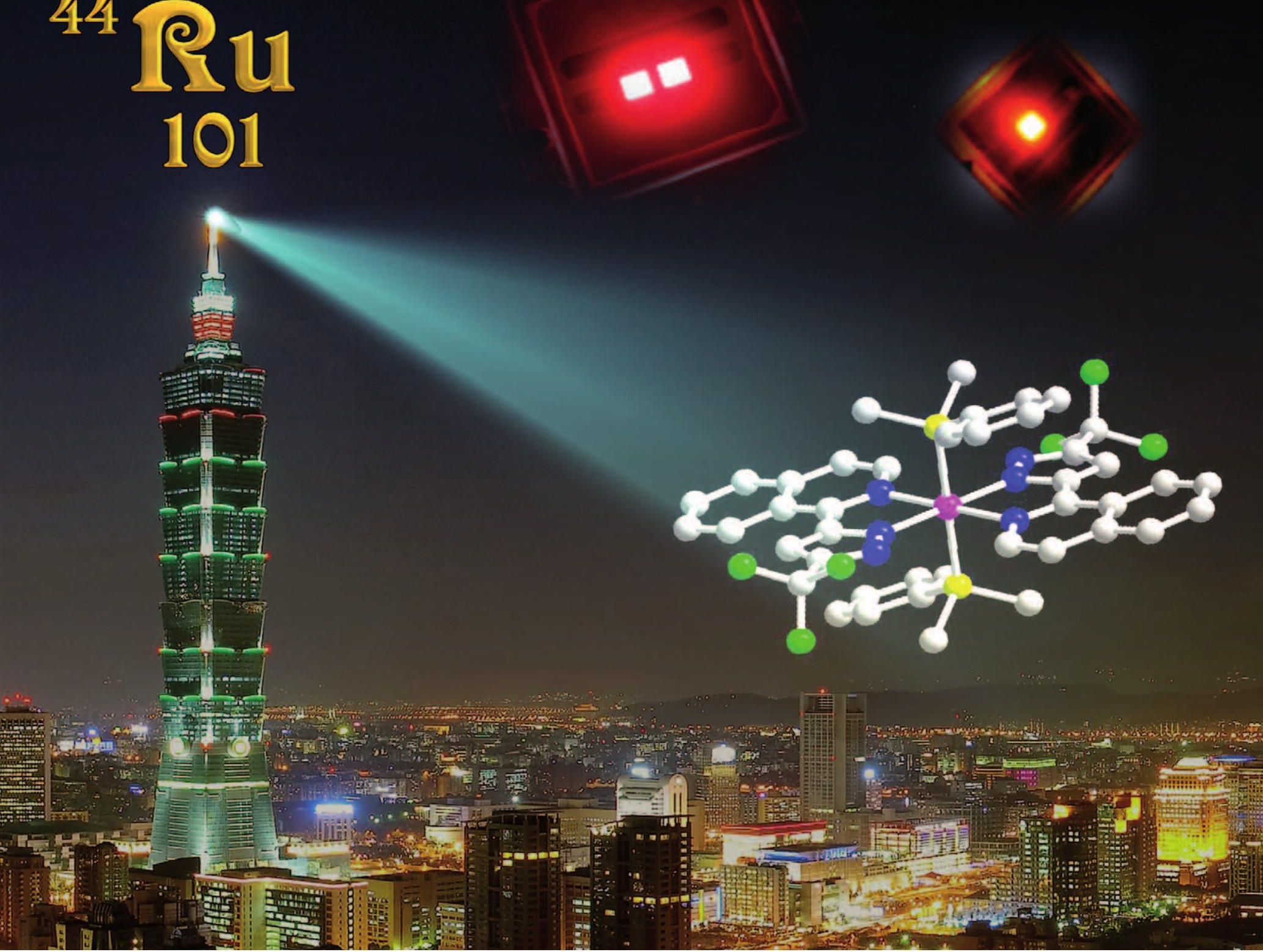

\section{TUTORIAL REVIEW}

Yun Chi and Pi-Tai Chou

Contemporary progress on neutral, highly emissive Os(II) and Ru(II) complexes
CRITICAL REVIEW

Paul A. Midgley, Edmund P.W. Ward, Ana B. Hungría and

John Meurig Thomas

Nanotomography in the chemical,

biological and materials sciences 


\title{
Contemporary progresses on neutral, highly emissive Os(II) and Ru(II) complexes
}

\author{
Yun $\mathrm{Chi}^{* a}$ and Pi-Tai Chou ${ }^{* b}$
}

Received 25th October 2006

First published as an Advance Article on the web 23rd February 2007

DOI: $10.1039 / \mathrm{b} 608951 \mathrm{~h}$

This tutorial review highlights recent and current advances in Os(II) and Ru(II) based luminescent complexes in view of their potential in providing models for photophysical properties and in serving as active materials in optoelectronic devices. It starts with a discussion of the fundamentals of pyridyl azolate chromophores and presents several prototypical designs that allow subtle variation of their basic properties. The third section of this article concerns the preparation of $\mathrm{Os}$ (II) and $\mathrm{Ru}(\mathrm{II})$ metal complexes and discusses the key factors that control their phosphorescence efficiencies and peak wavelengths. Attention is focused on the properties of their lowest lying excited states. In the last section, we present a series of related Os(II) complexes possessing pyridyl azolate, cyclometalated benzo $[h]$ quinoline, $\beta$-diketonates and quinolinates to demonstrate the power of fundamental basis to chemistry and theoretical approaches in rationalizing the corresponding photophysical behavior and hence to discuss the implications regarding their possible routes for future research.

\section{Introduction}

Luminescent transition-metal compounds constitute an important class of materials that has attracted much attention in the past half century. Thousands of compounds have been synthesized, and a very extensive literature has evolved in dealing with their fundamentals such as electrochemistry, photophysics and photochemistry. ${ }^{1}$ This is apparently driven by their wide potential for future applications in optical sensing and sensitization, and for developing new technologies

${ }^{a}$ Department of Chemistry, National Tsing Hua University, Hsinchu 300, Taiwan E-mail: ychi@mx.nthu.edu.tw; Fax: (+886)3-5720864

${ }^{b}$ Department of Chemistry, National Taiwan University, Taipei 10617, Taiwan E-mail: chop@ntu.edu.tw; Fax: (+886) 2-2369-5208 such as electrochemiluminescence, light-emitting diodes and even photovoltaics. ${ }^{2}$ Among the various synthetic processes that afford the luminous metal complexes, the diimine ligands (or polypyridine analogues) are known to react with osmium, ruthenium and iridium metal reagents in forming cationic complexes such as $\left[\mathrm{Os}(\mathrm{bpy})_{3}\right]^{2+},\left[\mathrm{Ru}(\mathrm{bpy})_{3}\right]^{2+}$ and $\left[\operatorname{Ir}(\mathrm{bpy})_{3}\right]^{3+}$, bpy $=2,2^{\prime}$-bipyridine, whereas the organic $\mathrm{N}$-heterocyclic compounds can react with iridium and platinum, giving a series of neutral, cyclometalated complexes such as $\left[\operatorname{Ir}(p p y)_{3}\right]$ and $\left[\mathrm{Pt}(\mathrm{ppy})_{2}\right]$, (ppy)H $=$ 2-phenylpyridine. ${ }^{3}$ As the phenyl substituent undergoes the so-called $\mathrm{C}-\mathrm{H}$ activation process, this ligand turns formally anionic during reaction, and thus the products carry zero positive charge and tend to possess a much higher volatility and good miscibility in the organic phase. In

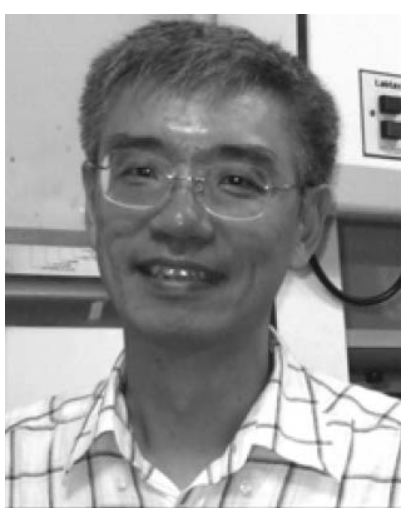

Yun Chi
Yun Chi obtained his PhD degree from the University of Illinois at Urbana-Champaign in 1986 (supervisor: Dr John $R$. Shapley), and pursued postdoctoral work for one year at MIT with Prof. Dietmar Seyferth. Having joined the faculty at National Tsing Hua University in 1987, he was promoted to the Chair Professor of Natural Sciences in 2003. His earlier academic endeavours cover the chemistry of transition-metal cluster complexes. His current research focuses on subjects involving preparation of chemical vapor deposition (CVD) precursors suitable for making metal-containing coatings and even nanomaterials, as well as synthesis of transition-metal based luminescent materials for organic light emitting diodes (OLED) and photovoltaic applications.

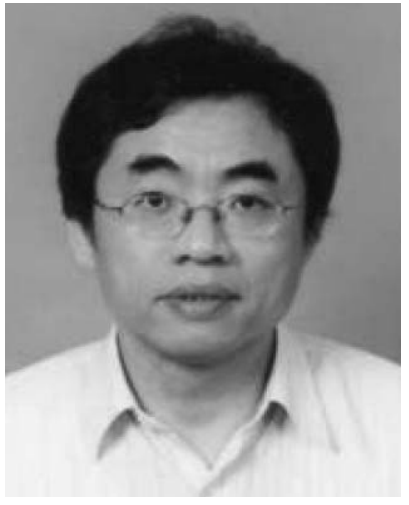

Pi-Tai Chou
Pi-Tai Chou received his PhD degree from Florida State University, Tallahassee, in 1985, and is currently a Chair Professor at the National Taiwan University (NTU). Prior to joining NTU, he was a DOE postdoctoral fellow at the University of California, Berkeley (1985-1987), an assistant professor at the University of South Carolina, Columbia (1987-1994) and a professor of National Chung Cheng University (19942000), where he was the departmental chairman from 1997 to 1999. His research interests are in the area of ultrafast laser spectroscopy, excited-state proton/charge transfer reaction and syntheses, photophysics, and applications of materials suited for $O L E D$, solar energy cells, and nanotechnology. 
contrast, the ionic complexes, due to the strong electrostatic attractions of the oppositely charged particles in the condensed phases, are significantly less volatile and become immiscible in a non-polar matrix.

These distinctive characteristics offer completely different opportunities in application. For example, neutral $[\operatorname{Ir}(p p y)]_{3}$ and its functionalized derivatives are excellent for the fabrication of organic light-emitting devices (OLEDs) using direct vacuum deposition, ${ }^{4}$ while its ionic counterparts are useful for making light-emitting electrochemical cells (LECs), in which the emissive layer requires an excess of mobile ions. ${ }^{5}$ Similarly, the ionic $\left[\mathrm{Os}(\mathrm{bpy})_{3}\right]^{2+}$ and $\left[\mathrm{Ru}(\mathrm{bpy})_{3}\right]^{2+}$ complexes are good for LECs. ${ }^{6}$ Moreover, the fabrication of an outstanding electroluminescent device, which showed fully reversible voltage-dependent switching between green and red light emission, has been accomplished using a semiconducting polymer combined with an ionic $\mathrm{Ru}$ complex. $^{7}$ Again, these type of complexes are quite unsuitable for fabricating high efficiency OLEDs due to their ionic nature. ${ }^{8}$ As a result, there is an urgent need to design and prepare certain neutral Os(II) and Ru(II) complexes, which are capable of exhibiting excellent emission quantum yields, suitable electrochemical potentials (i.e. the work function) and reversibility, thermal stabilities, enhanced volatility in vacuo, reduced tendency to form aggregates and good miscibility with the host materials, to fill the gap for their technical applications, particularly for OLEDs. This tutorial review will then survey reactions involving our recent and current work focusing on these neutral complexes, and present a brief overview of various facets in an attempt to explore possible future research directions.

\section{Ligand synthesis}

One prominent success in our recent progress lies in the exploitation of C-linked 2-pyridyl azoles as ligands to greatly extend the luminescent versatility in Os(II) and $\mathrm{Ru}(\mathrm{II})$ complexes. The high acidity of the azole $\mathrm{N}-\mathrm{H}$ bond makes $\mathrm{C}$-linked 2-pyridyl azole more reactive and able to extend the scope of the cyclometalation reaction, particularly for third row transition metal reagents, which are known to be less reactive compared with their first and second row counterparts.

At least two distinctive synthetic strategies have been employed to prepare the required C-linked pyridyl pyrazole ligands, for which the optimized reaction route is dependent on their substituents on the pyrazole segment, among which alkyl, fluorine substituted alkyl, and aryl substituents have been extensively employed, while the most frequently used architectures involve $\mathrm{CF}_{3}$, methyl, or tert-butyl substituted pyrazoles such as $\mathbf{L 1}, \mathbf{L} 2$ and $\mathbf{L} 3$. The preparation of the $\mathrm{CF}_{3}$ substituent $\mathbf{L} \mathbf{1}$ is best executed using a hydrazine cyclization reaction with a suitably prepared pyridyl diketone intermediate, which is obtained in situ from the base-catalyzed Claisen condensation using 2-acetylpyridine and ethyl trifluoroacetate. ${ }^{9}$ In contrast, preparation of alkyl substituted $\mathbf{L 2}$ or $\mathbf{L 3}$ can be achieved through the condensation of methyl picolinate with acetone or with pinacolone, followed by treatment with anhydrous hydrazine using the same cyclization method. ${ }^{10}$ Other pyrazole ligands such as $\mathbf{L 4}$, which is useful for executing an extensive emission color tuning, are also presented in Scheme 1.

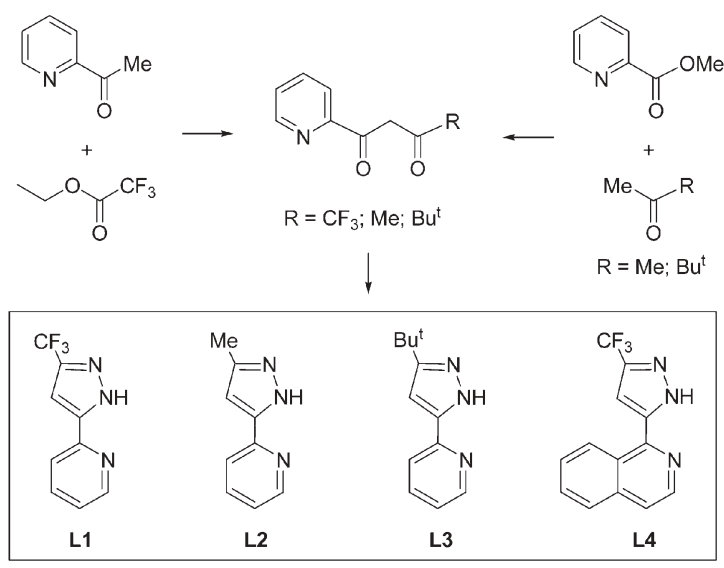

Scheme 1

Similar to the above mentioned pyrazole analogues, the related C-linked 1,2,4-triazoles are also frequently used as chelates in preparing luminescent metal complexes, and this may be connected to their similarity to polypyridyl ligands as well as coordinative properties. ${ }^{11}$ As shown in Scheme 2, the synthesis of the $\mathrm{CF}_{3}$ substituted, C-linked pyridyl 1,2,4-triazole L5 was achieved by the condensation of 2-pyridinecarboximidamide hydrochloride with the trifluoroacetic acid hydrazide; the latter is generated by mixing ethyl trifluoroacetate and hydrazine monohydrate. ${ }^{12}$ On the other hand, a convenient synthesis of the tert-butyl substituted L6 entails the direct reaction of 2-pyridinecarboxamidrazone with pivaloyl chloride in basic aqueous media, followed by dissolving the resulting precipitate in ethylene glycol and heating the mixture at $\sim 210^{\circ} \mathrm{C}$. ${ }^{13}$ One unique feature of this class of triazoles is that the metal chelation tends to form between the pyridyl site and the $\mathrm{N}-1$ nitrogen atom rather than the more congested N-4 site, due to the increased spatial interference.

Moreover, in terms of the electronic properties, the relatively strong $\sigma$-donor property of the aforementioned azolate unit, together with the good $\pi$-accepting ability of the second pyridyl fragment, provides a synergism of the electron delocalization over the whole ligand $\pi$ system as well as metal $d_{\pi}$ orbitals.

\section{Complexes with pyridyl azolate or equivalent}

\subsection{Carbonyl complexes}

The pyridyl azoles will readily react with the group 8 metal carbonyl using both their acidity $\mathrm{N}-\mathrm{H}$ bonding and adjacent pyridyl N-donor, to afford the cyclometalated products in a similar way to that of 2-phenylpyridine, which is far less

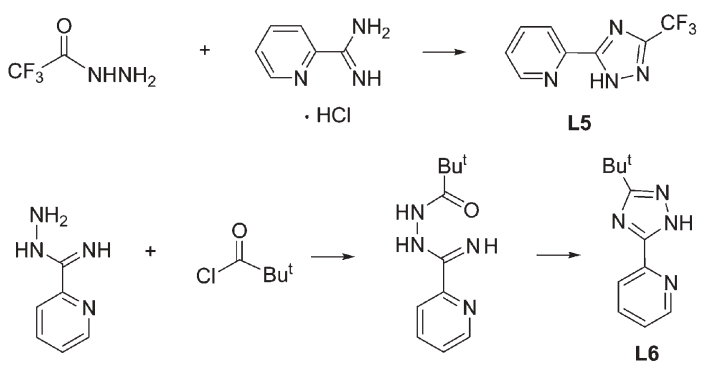

Scheme 2 
reactive due to the need to activate the ortho $\mathrm{C}-\mathrm{H}$ group. Furthermore, the C-linked 2-pyridyl azole belongs to a class of chelates for which the large difference in the electronic properties of the pyridyl (electron acceptor) and azolate (electron donor) fragment would render a larger ligandcentered $\pi \pi^{*}$ energy gap. Such a property is very desirable for generating blue phosphorescence if the metal $d_{\pi}$ energy can be largely suppressed using other ancillary ligands, such as $\mathrm{CO}$ with great $\pi$-accepting character.<smiles></smiles>

(1)

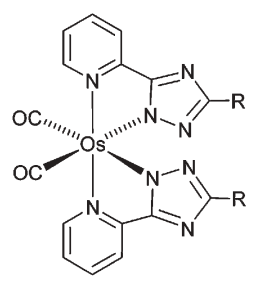

$\mathrm{R}=\mathrm{CF}_{3},(2)$ $\mathrm{R}=\mathrm{Bu}^{\mathrm{t}},(\mathbf{7})$

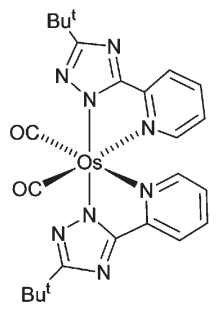

(8)
(3)

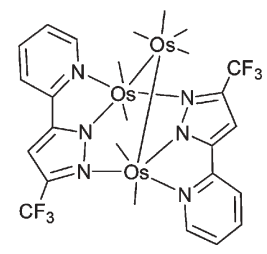

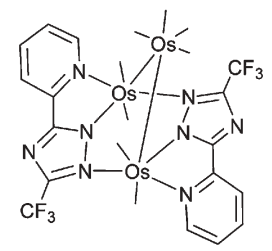

(4)
One of the important discoveries in the luminescent Os(II) complexes is the successful isolation of the pyridyl azolate complexes (1) and (2) from $\mathrm{Os}_{3}(\mathrm{CO})_{12} \cdot{ }^{14}$ In studying the possible mechanism that afforded these products, it is best to conduct the reactions using a $1: 3$ molar ratio of $\mathrm{Os}_{3}(\mathrm{CO})_{12}$ and corresponding azole chelates L1 (or L5) in refluxing diethylene glycol monoethyl ether (DGME). Thus, the novel triosmium pyrazolate and triazolate clusters (3) and (4) are obtained in good yields. ${ }^{15}$ The ORTEP diagram of $\mathbf{4}$ is depicted in Fig. 1, showing the V-shaped triosmium skeleton with two anti-symmetric pyridyl trizolate ligands residing at

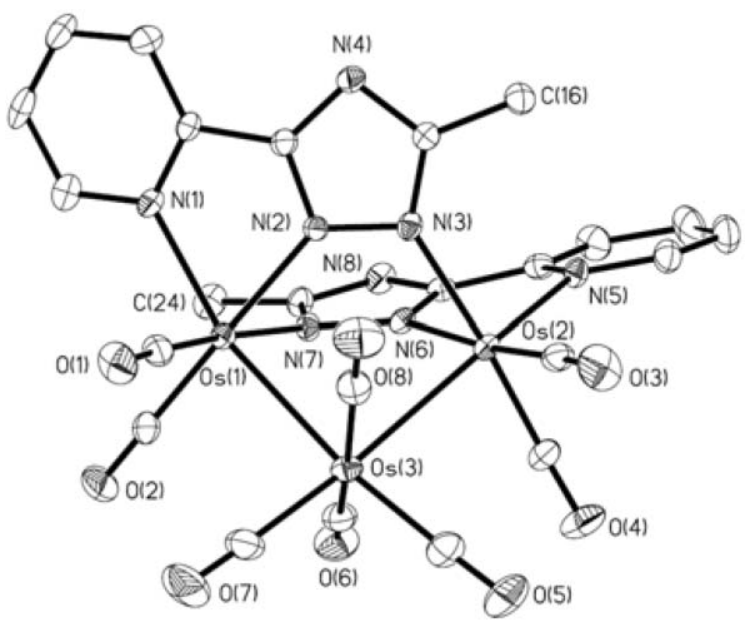

Fig. 1 ORTEP diagram of 4; fluorine atoms on carbon atoms C(16) and $\mathrm{C}(24)$ were removed for clarity; selected bond distances: Os(1)$\operatorname{Os}(3)=2.8401(4), \operatorname{Os}(2)-\operatorname{Os}(3)=2.8440(4)$ and $\operatorname{Os}(1) \cdots \operatorname{Os}(2)=$ 3.771(1) and angles: Os(1)-Os(3)-Os(2) = 83.127(10) ${ }^{\circ}$. mutual perpendicular positions and all three $\mathrm{N}$ donors linked to only the Os termini. The status of each as a critical reaction intermediate is also unambiguously confirmed, as further treatment of $\mathbf{3}$ with $\mathbf{L 1}$ (or $\mathbf{4}$ with $\mathbf{L 5}$ ) has afforded the blue phosphorescent $1\left(\lambda_{\max } \sim 430 \mathrm{~nm}\right)$ and $2\left(\lambda_{\max } \sim 420 \mathrm{~nm}\right.$ in $\mathrm{CH}_{2} \mathrm{Cl}_{2}$ ) in high yields, based on the consumption of the intermediate $\mathbf{3}$ or $\mathbf{4}$. However, it is also tempting to propose the existence of a second, non-isolated, dinuclear intermediate (5) via the elimination of the central, less connected $\mathrm{Os}(\mathrm{CO})_{4}$ metal unit. Support for this hypothesis is provided by the isolation of a related, diosmium diketonate complex (6) from direct treatment of $\mathrm{Os}_{3}(\mathrm{CO})_{12}$ with an excess of dipivaloylmethane in a sealed autoclave under prolonged heating at $190^{\circ} \mathrm{C}^{16}$
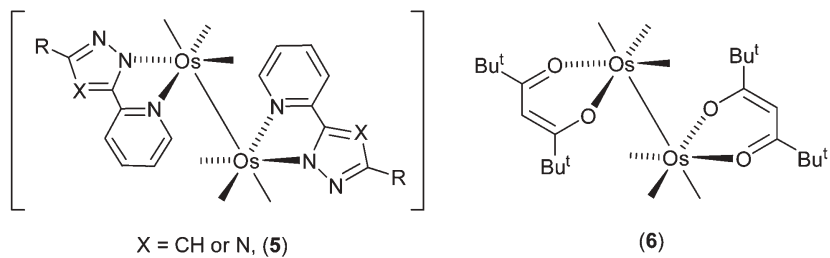

(6)

We are also interested in exploring the effects of relative ligand orientation versus the photophysical properties. For reactions using the triazole chelate, two isomeric complexes, (7) and (8), were observed for the direct treatment of L6 with $\mathrm{Os}_{3}(\mathrm{CO})_{12} \cdot{ }^{17}$ Separation of isomers was achieved using their markedly different solubility in acetone, where the less soluble isomer 7, which is structurally related to the $\mathrm{CF}_{3}$ substituted 2 , could be easily obtained as a crystalline solid, while isolation of $\mathbf{8}$, with both of its triazolate fragments residing at the transdisposition, required slow diffusion of hexane vapor into a saturated acetone solution at room temperature.

Despite their structural isomerism, remarkable differences in luminescence behavior were resolved between 7 and 8 . Table 1 compiles their photophysical data, together with those deriving from 1 and 2. Complex 7 exhibits strong emission, with a quantum yield of 0.42 , for which distinct vibronic peak maxima appeared at $\sim 455,480$, and $507 \mathrm{~nm}$ in degassed $\mathrm{CH}_{3} \mathrm{CN}$ at $298 \mathrm{~K}$. With a similar emission frequency and profile, in sharp contrast, the emission intensity of $\mathbf{8}$ is much weaker, showing quantum efficiency as low as $4.6 \times 10^{-4}$ under identical conditions. This weak phosphorescence also correlates well with the observed fast relaxation dynamics, in which the lifetime of phosphorescence for $\mathbf{8}$ was measured to be as short as $26 \mathrm{~ns}$ as opposed to $\sim 40 \mu$ s for 7 in degassed $\mathrm{CH}_{3} \mathrm{CN}$.

According to conventional wisdom, thermal population to a MC dd state, which results in weakening of the metal-ligand interaction due to its anti-bonding character, may play a key

Table 1 Photophysical properties of blue-emitting Os(II) complexes in degassed acetonitrile at $\mathrm{rt}$

\begin{tabular}{llllc}
\hline Entry & $\lambda_{\text {max }}^{\text {abs }} / \mathrm{nm}$ & $\lambda_{\text {max }}^{\mathrm{em}} / \mathrm{nm}$ & Q.Y. $\Phi$ & $\tau_{\text {obs }}(\mu \mathrm{s})$ \\
\hline $\mathbf{1}$ & 311 & $430,457,480$ & 0.14 & 18.5 \\
$\mathbf{2}$ & 307 & $420,446,468$ & 0.23 & 2.9 \\
$\mathbf{7}$ & 333 & $455,480,507$ & 0.42 & 39.9 \\
$\mathbf{8}$ & 340 & $460,483,515$ & 0.00046 & 0.026 \\
\hline
\end{tabular}


role to promote the radiationless transition in $\mathbf{8}$. However, this possibility was ruled out, as none of the four lowest excited states, including two singlet and two triplet manifolds based on the DFT calculation, possess the anticipated MC dd character. The thermal inaccessibility of the dd excited state is believed to come from the strong ligand field strength of the azolates as well as the $\mathrm{CO}$ ligands. As for a more plausible rationalization, the lowest energy $T_{1}$ states in $\mathbf{8}$ could be reasonably attributed to a ${ }^{3} \pi \pi^{*}$ manifold, mixed with a small amount of the ${ }^{3}$ MLCT character. Thus, population of the $\mathrm{T}_{1}$ excited state causes the shift of the electron density from the Os(II) metal, CO ligands and triazolate to the pyridyl moiety, resulting in a reduction of the already weakened pyridine-to-Os(II) metal interactions in $\mathbf{8}$, i.e., a sort of trans-effect in the excited state. As a result, the potential energy surface of $\mathrm{T}_{1}$ might be so shallow that, under extreme conditions, a surface crossing between $S_{0}$ and $T_{1}$ is possible. As shown in Fig. 2, upon excitation, fast $\mathrm{S}_{1}-\mathrm{T}_{n}$ intersystem crossing must take place due to the heavy metal (osmium) enhanced spin-orbit coupling. According to the theoretical approach, ${ }^{17}$ it is plausible that intersystem crossing proceeds from $S_{1}$ to $T_{2}$ due to their closeness in energy, followed by a fast rate of $T_{2}$ to $T_{1}$ internal conversion $\left(\leqslant 1 \mathrm{ps}^{-1}\right)$. After population equilibrium, 8 can be thermally activated to certain vibrational levels close to the surface crossing to execute the radiationless deactivation through facile metal-ligand bond stretching. Thus, a dominant $T_{1} \rightarrow S_{0}$ radiationless transition caused by a "loose bolt" effect might take place upon thermal activation. ${ }^{18}$

This observation allows a parallel comparison with the related complexes $\left[\operatorname{Ir}(\mathrm{ppy})_{3}\right]$ and $\left[\operatorname{Ir}(\mathrm{ppz})_{3}\right],(\mathrm{ppz}) \mathrm{H}=N$-phenyl pyrazole, for which isolation of two geometrical isomers were also documented. ${ }^{19}$ Structural and spectroscopic data suggest that the facial isomers have the stronger and more evenly distributed metal-ligand bonding, exhibiting bright phosphorescence in both fluid and solid states. In contrast, the meridional isomers have much greater bond length alternations caused by the differing trans influences of anionic phenyl and neutral $\mathrm{N}$ donors (or azolate $v s$ pyridine) and are thus significantly less emissive. Naturally, this greater bond

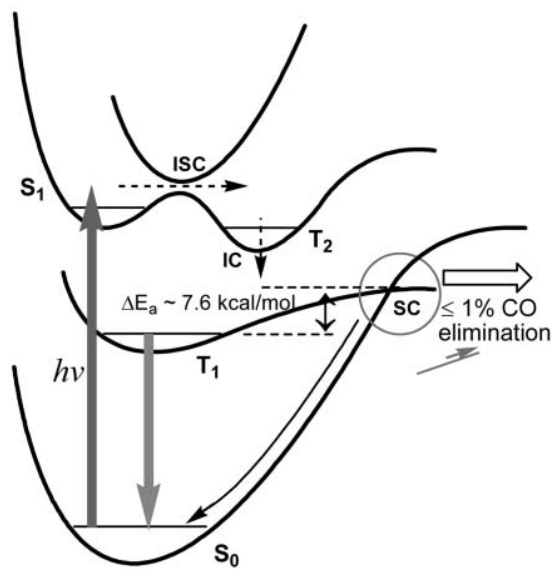

Fig. 2 Energy levels of the lower-lying excited states and the proposed relaxation pathway for complex $\mathbf{8}$. ISC: intersystem crossing, IC: internal conversion. SC: surface crossing.

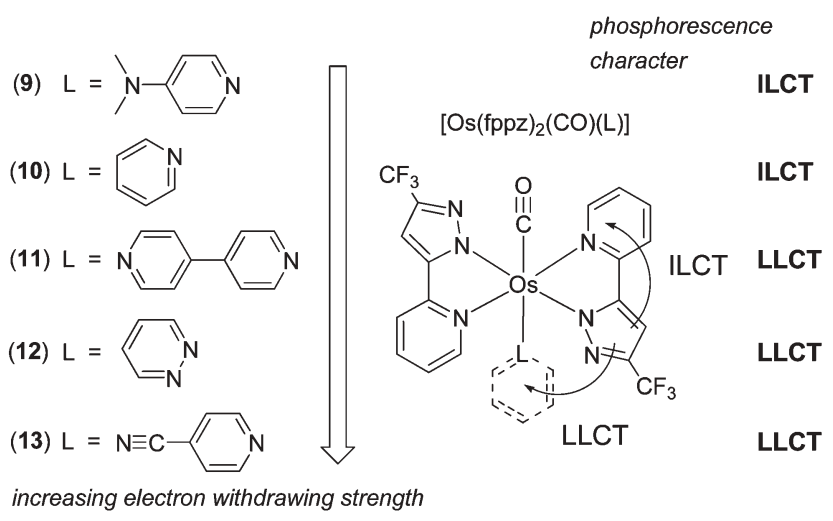

Scheme 3

strength alternation of the meridional isomers then induces a similar "loose bolt" effect, ${ }^{18}$ which is more likely responsible for the rapid radiationless deactivation observed in this $\operatorname{Ir}(\mathrm{III})$ system.

Moreover, treatment of complex 1 with nitrogen donor ligand led to the formation of a new series of Os(II) complexes with the formula $\left[\mathrm{Os}(\mathrm{fppz})_{2}(\mathrm{CO})(\mathrm{L})\right],(\mathrm{fppz}) \mathrm{H}=\mathbf{L 1}, \mathrm{L}=$ 4-dimethylaminopyridine (9), $\mathrm{L}=$ pyridine $(\mathbf{1 0}), \mathrm{L}=$ 4,4'-bipyridine (11), L = pyridazine (12), L = 4-cyanopyridine (13), for which the remaining carbonyl and one N-heterocyclic ligand are located at the axial positions (see Scheme 3). ${ }^{20}$ Variation of the axial N-heterocyclic ligand leads to remarkable changes in photophysical properties in that the energy gap of the lowest lying transition and hence the phosphorescence peak wavelength can be fine-tuned.

For complexes $\mathbf{9}$ and 10, the axial nitrogen donor ligand possesses a relatively electron rich aromatic $\pi$ system, which discourages its participation in the lowest energy electronic transition. As a result, the phosphorescence originates from a combination of intra-ligand ${ }^{3} \pi \pi^{*}\left({ }^{3}\right.$ ILCT) and ${ }^{3}$ MLCT to the pyridyl fragments of the fppz chelates (see Scheme 3). This is confirmed by the observation of only an $18 \mathrm{~nm}$ red-shifted emission wavelength for complex $\mathbf{1 0}$ upon changing solvents from cyclohexane $(487 \mathrm{~nm})$ to acetonitrile $(\sim 505 \mathrm{~nm})$. In sharp contrast, complexes 11-13 exhibit mainly ligand-toligand charge transfer (LLCT) transition, showing a transfer of electron density from the equatorial pyrazolate fragment to the axial $\mathrm{N}$ donor ligand due to the extended $\pi$-conjugation (4,4'-bipyridine) or the presence of an electron withdrawing atom or substituent ( $c f$. pyridazine and 4-cyanopyridine). The phosphorescence thus reveals strong solvent-polarity dependence, resulting in a large tuning in emission wavelength, e.g. from 560 (in $\mathrm{C}_{6} \mathrm{H}_{12}$ ) to $665 \mathrm{~nm}$ (in $\mathrm{MeCN}$ ) and from 603 (in $\mathrm{C}_{6} \mathrm{H}_{12}$ ) to $710 \mathrm{~nm}$ (in $\mathrm{MeCN}$ ) for complexes $\mathbf{1 1}$ and 13, respectively. These results clearly demonstrate that a simple derivatization of the axial $\mathrm{N}$-heterocyclic ligand has drastically altered the excitation properties per se from ILCT to LLCT transition.

\subsection{Hydride complexes}

The reactions of $\mathbf{4}$ with excess $\mathrm{PPh}_{2} \mathrm{Me}$ produced two interchangeable hydride complexes (14 and (15), for which the DGME solvent could plausibly be the supplier of the 
Table 2 Photophysical properties of Os(II) complexes in solution and solid states at $\mathrm{rt}$

\begin{tabular}{lllll}
\hline Entry & $\lambda_{\max }^{\mathrm{abs}} / \mathrm{nm}$ & $\lambda_{\max }^{\mathrm{em}} / \mathrm{nm}$ & Q.Y. $\Phi$ & $\tau_{\text {obs }} / \mu \mathrm{s}$ \\
\hline $\mathbf{1 4}$ & $273,307,373$ & $543(475)^{b}$ & 0.01 & 0.4 \\
$\mathbf{1 5}$ & $265,303,406$ & $553(510)$ & 0.38 & 6.7 \\
$\mathbf{1 6}$ & $405,454,542$ & $617(618)^{b}$ & $0.50(0.21)^{b}$ & $0.86(0.63)^{b}$ \\
$\mathbf{1 7}$ & $411,456,553$ & $632(655)$ & $0.19(0.29)$ & $0.73(0.61)$ \\
$\mathbf{1 8}$ & $406,466,560$ & $649(670)$ & $0.25(0.10)$ & $0.63(0.44)$ \\
$\mathbf{1 9}$ & $403,457,543$ & $617(631)$ & $0.62(0.24)$ & $0.96(0.18)$ \\
$\mathbf{2 0}$ & $409,463,551$ & $632(637)$ & $0.14(0.20)$ & $0.84(0.15)$
\end{tabular}

${ }^{a}$ Spectra of $\mathbf{1 4}$ and $\mathbf{1 5}$ were measured in cyclohexane, while those of 16-20 were measure in $\mathrm{CH}_{2} \mathrm{Cl}_{2}$ solution. ${ }^{b}$ Data in parentheses were measured as solid thin film at rt.

observed hydride ligands. ${ }^{15}$ As for the UV/Vis spectra, the absorption peak of $373 \mathrm{~nm}$ in $\mathbf{1 4}$ is notably red shifted to $\sim 406 \mathrm{~nm}$ in $\mathbf{1 5}$ (Table 2). Accordingly, the $\pi$-accepting CO ligand in $\mathbf{1 4}$ should lead to a decrease of its trans-triazolate $\pi$-energy level, while the strong $\sigma$-donating hydride ligand would increase its $\pi^{*}$ energy of the trans-pyridyl group, resulting in an increase of the ILCT energy gap. Conversely, an opposite effect is thus expected for $\mathbf{1 5}$ in that the $\pi$ electron deficiency in the pyridyl moiety should lead to a decrease of the ILCT gap, consistent with the corresponding absorption spectral differences between $\mathbf{1 4}$ and $\mathbf{1 5}$.
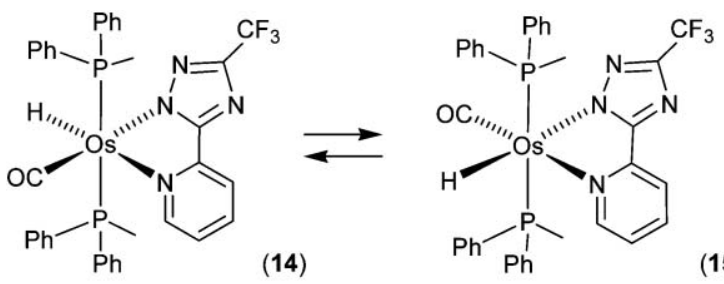

To account for the emission properties, DFT calculation has shown that the lowest energy $T_{1}$ state in $\mathbf{1 4}$ mainly consists of an appreciable portion of carbonyl-to-pyridine LLCT transition. Thus, the photoexcitation would reduce the $\pi$-accepting strength of $\mathrm{CO}$ ligand and, hence, the weakening the Os-CO bond strength would result in a significant distortion of the potential energy surface with respect to that of the ground state. In sharp contrast, the lowest energy $T_{1}$ state of $\mathbf{1 5}$ involves essentially no contribution from the $\mathrm{CO}$ ligand, resulting in a mirror image between absorption $\left(S_{0} \rightarrow T_{1}\right)$ and efficient phosphorescence. Evidence for this proposed mechanism lies in the $\sim 40$ fold difference of phosphorescence intensity between $14\left(\Phi_{\mathrm{p}} \sim 0.01\right)$ and $\mathbf{1 5}\left(\Phi_{\mathrm{p}} \sim 0.38\right)$ in room temperature degassed cyclohexane solution. Again, the results manifest the specific weak metal-ligand bond that triggers a similar loose bolt effect, ${ }^{18}$ resulting in an increase of the radiationless transition. We thus believe that these results regarding the enhancement of radiationless deactivation provide a pertinent fundamental basis for the future design and preparation of highly efficient phosphorescent emitters.

\subsection{Diphosphine osmium derivatives}

Owing to its strong $\sigma$-donating property, phosphine serves as a desirable ligand for tuning the emission of transition metal complexes. For example, the concept of preparing red emitting
Os(II) based complexes can be illustrated using the previously discussed blue-emitting complexes $\mathbf{1}$ and $\mathbf{2} .^{21}$ In view of their $\pi \pi^{*}$ character mixed with MLCT contribution for the lowest lying transition, one facile way to red-shift the emission is to increase the $M C \mathrm{~d}_{\pi}$ energy level. This can be accomplished via replacing the strong $\pi$-accepting $\mathrm{CO}$ by a more electron donating ligand such as phosphine. The desired synthesis was then initiated by the treatment of respective Os(II) complexes 1 and 2 with $\mathrm{Me}_{3} \mathrm{NO}$ to eliminate $\mathrm{CO}$ ligands, followed by addition of corresponding phosphine ligands. A related onepot synthetic strategy, starting from $\mathrm{Os}_{3}(\mathrm{CO})_{12}$, gives us the desired Os(II) complexes 16-20 in much improved $(\geqslant 70 \%)$ yields, and hence has a great advantage in scaling up for possible industrial applications. ${ }^{22}$ Structural drawings of several representative complexes are depicted below:

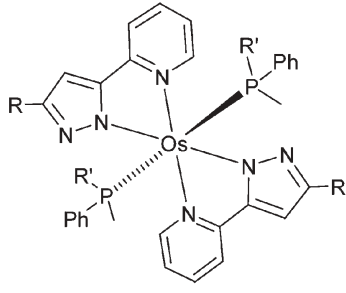

$\mathrm{R}=\mathrm{CF}_{3}, \mathrm{R}^{\prime}=\mathrm{Ph},(\mathbf{1 6})$

$\mathrm{R}=\mathrm{CF}_{3}, \mathrm{R}^{\prime}=\mathrm{Me},(17)$

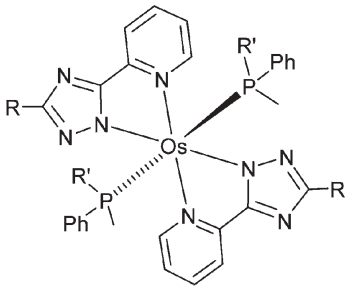

$\mathrm{R}={ }^{\mathrm{t}} \mathrm{Bu}, \mathrm{R}^{\prime}=\mathrm{Ph},(18)$

$\mathrm{R}=\mathrm{CF}_{3}, \mathrm{R}^{\prime}=\mathrm{Ph},(19)$

$\mathrm{R}=\mathrm{CF}_{3}, \mathrm{R}^{\prime}=\mathrm{Me},(\mathbf{2 0})$
It is noted that both pyridyl azolate ligands in complexes $\mathbf{1 6}$ 20 occupied the planar arrangement around the Os(II) atom. Such a configuration is in sharp contrast to their cationic bis(diimine) counterparts, for which the diimine ligands typically reside at the cis-dispositions. We tentatively attributed this change of ligand orientation to the concurrent formation of a pair of $\mathrm{H}$-bonds between the ortho- $\mathrm{CH}$ group of pyridine and the non-coordinated $\mathrm{N}$ atom of adjacent, azolate fragments. Moreover, the UV/Vis spectra of these Os(II) complexes showed distinct absorption in visible region (Table 2). The second lowest energy band, around 454-466 nm can be ascribed to a spin-allowed metal to ligand charge transfer ( ${ }^{1}$ MLCT) transition, while the lowest energy band with $\varepsilon<500 \mathrm{M}^{-1} \mathrm{~cm}^{-1}$ can be assigned to a state involving a mixture of both ${ }^{3} \pi \pi^{*}$ and ${ }^{3} \mathrm{MLCT}$ characters.

For the emission spectra, complex 17, bearing $\mathrm{PPhMe}_{2}$ groups, reveals a $\sim 15 \mathrm{~nm}$ bathochromic shift in $\lambda_{\max }$ compared with the $\mathrm{PPh}_{2} \mathrm{Me}$ substituted derivative 16 (see Table 2), which can be rationalized by an increase of the Os(II) $\mathrm{d}_{\pi}$ energy level due to the poor $\pi$-accepting strength of $\mathrm{PPhMe}_{2}$ (Table 1). Based on the negligible difference of the emission peak wavelengths between $\mathbf{1 6}$ and $\mathbf{1 9}(617 \mathrm{~nm})$ or $\mathbf{1 7}$ and $\mathbf{2 0}$ $(632 \mathrm{~nm})$, we concluded that the triazolate segment showed only a minimal amount of hypsochromic displacement, although the $\pi$-accepting character should be greater than that of the pyrazolate analogue. Moreover, changing the substituent on the triazolate from tert-butyl to $\mathrm{CF}_{3}$ has caused a notable blue-shifting by lowering of the metal $\mathrm{d}_{\pi}$ energy, and is revealed by the decrease of emission $\lambda_{\max }$ of $\mathbf{1 8}$ with respect to 19. Finally, the observed lifetimes of $c a .0 .6-0.9 \mu \mathrm{s}$ in degassed $\mathrm{CH}_{2} \mathrm{Cl}_{2}$ solution are considerably shorter than those 
of most reported red-emitting $\operatorname{Ir}(\mathrm{III})$ complexes, implying that the OLED devices fabricated with Os complexes could exhibit reduced triplet-triplet annihilation. This is a very important factor required for fabrication of high efficiency, phosphorescent OLEDs. Recently, such a class of Os(II) phosphors has even been utilized for fabrication of high efficiency whiteemitting OLEDs. ${ }^{23}$

\subsection{Tuning emission to near-infrared}

As for further extending the emission toward far visible or even near-IR (NIR), strategic design using other ligands for the Os(II) complexes is necessary. The experiment for achieving the NIR emission required a tridentate ligand, 6-(5-trifluoromethyl-pyrazol-3-yl) 2,2'-bipyridine (fpbpy)H, which was obtained using Claisen condensation involving 6-acetyl2,2'-bipyridine and ethyl trifluoroacetate, followed by treatment with hydrazine hydrate according to the documented procedures. The subsequent treatment of $\mathrm{Os}_{3}(\mathrm{CO})_{12}$ with excess of (fpbpy)H would eventually give a mixture of parent and daughter complexes (21) and (22), which are related by the removal of one $\mathrm{CO}$ ligand at elevated temperature. ${ }^{24}$

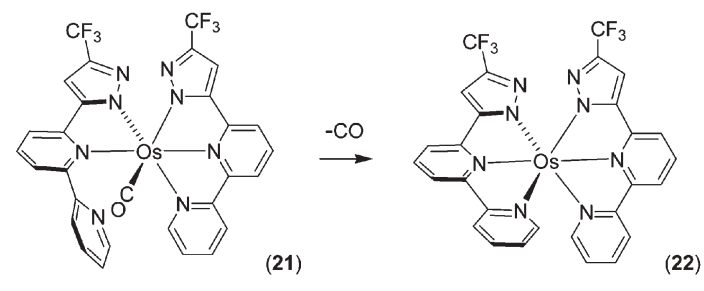

As shown in Table 3, complex 21 exhibited a dark-red emission at $655 \mathrm{~nm}$ and with $\Phi=0.0017$ and $\tau=13.4 \mathrm{~ns}$ in the degassed $\mathrm{MeCN}$ at rt. For the corresponding complex 22, the emission peak was located at $935 \mathrm{~nm}$ in a $77 \mathrm{~K}$ acetonitrile matrix, while the emission quantum yield and observed lifetime were measured to be 0.14 and $597 \mathrm{~ns}$, giving a radiative lifetime of $4.3 \mu \mathrm{s}$. Thus, in the conversion from 21 to 22, i.e. via removal of a CO ligand from the Os(II) center, an extensively large tuning of phosphorescence was achieved. This phenomenon can be qualitatively rationalized by the latent effect of strong $\pi$-accepting CO ligand, which lowers the $\mathrm{d}_{\pi}$ energy of Os(II) cation, hence increasing the MLCT gap in 21 together with the disruption of the $\pi$ conjugation due to the detachment of one pyridyl ligand coordination. For 22, the negligible NIR emission at $298 \mathrm{~K}$ manifests the fate of energy gap law, which theoretically predicts that the rate of radiationless deactivation increases as the emission gap decreases due to the matching of wavefunctions between the emitting state and highly vibrational levels of the ground electronic state, resulting in a fast $\mathrm{T}_{1} \rightarrow \mathrm{S}_{0}$ internal conversion, followed by the solvent (or lattice in the solid state) deactivation. This quenching mechanism, per se, is intrinsic

Table 3 Photophysical properties of $\mathbf{2 1}$ and $\mathbf{2 2}$ in acetonitrile

\begin{tabular}{llcccc}
\hline & $\lambda_{\text {max }}^{\text {abs }} / \mathrm{nm}$ & $\lambda_{\max }^{\mathrm{em}} / \mathrm{nm}$ & Q.Y. $\Phi$ & $\tau_{\mathrm{obs}}$ & $\tau_{\mathrm{r}}$ \\
\hline $\mathbf{2 1}$ & 385,515 & $655^{a}$ & $0.0017^{a}$ & $13.4 \mathrm{~ns}$ & $7.9 \mu \mathrm{s}$ \\
$\mathbf{2 2}$ & $468,650,715$ & $935^{b}$ & $0.14^{b}$ & $597 \mathrm{~ns}$ & $4.3 \mu \mathrm{s}$ \\
$a$ & The emission was detected at room temperature fluid state. ${ }^{b}$ The \\
emission was detected at $77 \mathrm{~K}$ in frozen matrix.
\end{tabular}

and hence is the main obstacle if one is interested in designing highly emissive transition metal complexes in the NIR region. Since energy gap law is particularly efficient for high frequency vibrational motions, e.g. $\mathrm{C}-\mathrm{H}$ and $\mathrm{O}-\mathrm{H}$ stretching, deuterium isotope substitution on ligands is considered to be one possible resolution.

\subsection{Diphosphine ruthenium complexes}

In view of the practical concern such as cost, ruthenium apparently gains advantage over the third row counterpart osmium. However, designing highly emissive, neutral Ru(II) complexes suited for OLEDs is non-trivial. First of all, the weaker ligand field strength for the second row elements requires the use of strong field ligands such as phosphine to increase the energy gap of the metal-centered dd transition, so that the radiationless deactivation associated with the metalmetal and/or metal-ligand bond stretching can be significantly suppressed. Moreover, as revealed in the ionic $\left[\mathrm{M}(\mathrm{bpy})_{3}\right]^{2+}$ system, $\mathrm{M}=\mathrm{Ru}$ and $\mathrm{Os}$, the relatively high oxidation potential in $\mathrm{Ru}(\mathrm{II})$ versus that of its third row Os(II) analogues would destabilize the MLCT excited state and cause a blue-shifting of the emission signal. This demands the employment of 1-isoquinolyl substituted chromophores in assembling the neutral $\mathrm{Ru}$ (II) complexes to compensate for the unfavorable metal oxidation potential in the generation of saturated red emission.
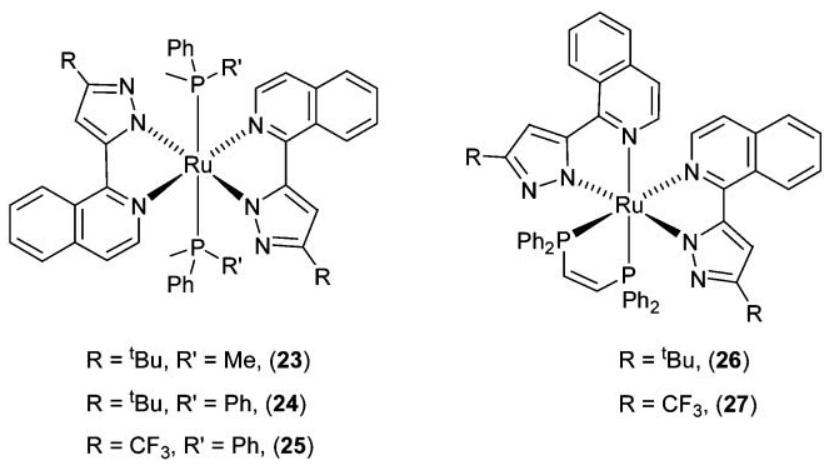

Accordingly, a series of $\mathrm{Ru}(\mathrm{II})$ complexes, 23-25, were synthesized following the same synthetic scheme established for their Os(II) counterparts. ${ }^{25}$ As shown in their photophysical data listed in Table 4, intense phosphorescence was

Table 4 Photophysical properties of $\mathrm{Ru}(\mathrm{II})$ complexes 23-27 in $\mathrm{CH}_{2} \mathrm{Cl}_{2}$ and solid state at $\mathrm{rt}$

\begin{tabular}{llccc}
\hline Entry & $\lambda_{\text {max }}^{\text {abs }} / \mathrm{nm}$ & $\lambda_{\max }^{\mathrm{em}} / \mathrm{nm}^{a}$ & Q.Y. $\Phi^{a}$ & $\tau_{\mathrm{obs}} / \mu \mathrm{s}$ \\
\hline $\mathbf{2 3}$ & $363,462,580^{b}$ & 718 & - & - \\
& & $(709)$ & $(0.02)$ & $(1.06)$ \\
$\mathbf{2 4}$ & $361,455,566^{b}$ & 700 & - & - \\
& & $(682)$ & $(0.02)$ & $(0.64)$ \\
$\mathbf{2 5}$ & $353,446,523^{b}$ & 636 & 0.01 & 0.10 \\
& & $(632)$ & $(0.24)$ & $(1.82)$ \\
$\mathbf{2 6}$ & $356,368,408,470^{b}$ & 637 & 0.08 & 0.06 \\
& & $(609)$ & $(0.21)$ & $(2.1)$ \\
$\mathbf{2 7}$ & $345,369,390,445^{b}$ & 596 & 0.002 & 0.02 \\
\multicolumn{5}{l}{ Data in parentheses were measured as thin solid film at $\mathrm{rt}^{b} \mathrm{~A}$} \\
\multicolumn{7}{l}{ very broad absorption signal. } \\
\hline
\end{tabular}


obtained in the solid state with $\lambda_{\max }$ at $709 \mathrm{~nm}, 682 \mathrm{~nm}$ and $632 \mathrm{~nm}$, respectively. In good agreement with the ${ }^{3}$ MLCT emission characteristics, the $\mathrm{PPh}_{2} \mathrm{Me}$ derivative $\mathbf{2 4}$ exhibits a $\sim 27 \mathrm{~nm}$ hypsochromic shift in emission $\lambda_{\max }$ in comparison to the $\mathrm{PPhMe}_{2}$ anchored 23, the result of which can be rationalized by a decrease of the $\mathrm{Ru}$ (II) $d_{\pi}$ energy level due to the increase of $\pi$-accepting strength. For complex 25, an even more notable hypsochromic shift of $50 \mathrm{~nm}$ was achieved. This is apparently caused by the electron withdrawing effect of the $\mathrm{CF}_{3}$ substituents on pyrazolate, which has the function of lowering the electron density at the Ru(II) center. As a result, high efficiency red-emitting OLEDs were fabricated using 25 as dopant.

Having gained the experience from the Os(II) complexes (vide supra), we also investigated the possible influence of changing the trans arrangement of phosphine ligands to the $\mathrm{cis}$ arrangement; this can be done by employing the rigid cis-1,2bis(diphenylphosphino) ethylene as ancillary ligand. ${ }^{26}$ Remarkably, the emission showed a further blue shift to 609 and $559 \mathrm{~nm}$ in solid state for the cis complexes $\mathbf{2 6}$ and $\mathbf{2 7}$, respectively. Moreover, emergence of a ${ }^{3} \pi \pi^{*}$ contribution for 27 is supported by the appearance of a second emission $\lambda_{\max }$ at $581 \mathrm{~nm}$ due to the vibronic coupling. This is apparently attributed to the relatively stronger $\mathrm{Ru}-\mathrm{P}$ bonding, as revealed by the solid state structural data, which stabilized the $\mathrm{Ru} \mathrm{d}_{\pi}$ electron and then reduced the MLCT contribution at the lowest lying excited state.

\subsection{Cyclometalated Ru(II) complexes}

To probe the luminescent behavior of cyclometalated ligand on the Ru(II) metal center, we repeated the direct synthesis of dicarbonyl complex (28) using benzo[ $h]$ quinoline and carbonyl reagent $\mathrm{Ru}_{3}(\mathrm{CO})_{12} \cdot{ }^{27}$ Upon treatment of 28 with $\mathrm{Me}_{3} \mathrm{NO}$, followed by addition of phosphine, one benzo[h]quinolinate ligand underwent a $180^{\circ}$ rotation around the $\mathrm{Ru}(\mathrm{II})$ metal center, giving the corresponding phosphine substituted derivatives (29) and (30), respectively. ${ }^{28}$
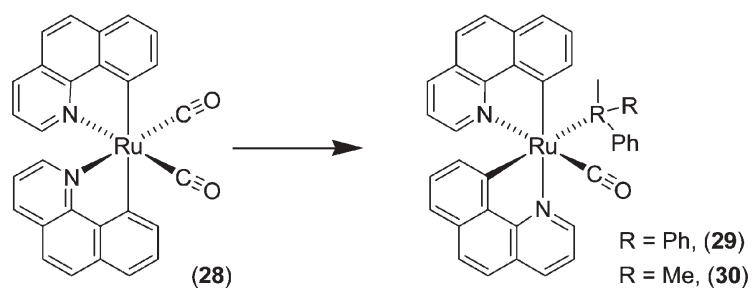

As depicted in Table 5, complex $\mathbf{2 8}$ was nearly non-emissive in room temperature $\mathrm{CH}_{2} \mathrm{Cl}_{2}$ solution, but revealed decent emission along with well-resolved vibronic progression in the $77 \mathrm{~K} \mathrm{CH}_{2} \mathrm{Cl}_{2}$ matrix. In sharp contrast to this observation, phosphine complexes $\mathbf{2 9}$ and $\mathbf{3 0}$ showed a broad, structureless phosphorescence at 571 and $575 \mathrm{~nm}$ at $\mathrm{rt}$ and at 553 and $556 \mathrm{~nm}$ at $77 \mathrm{~K}$, respectively. In light of the DFT calculation, we observed that the percentage of MLCT contribution in the lowest lying $\mathrm{T}_{1}$ state of $\mathbf{2 8}(10.2 \%)$ is significantly less than those of $\mathbf{2 9}$ and $\mathbf{3 0}(\geqslant 40 \%)$, which is in good agreement with the spectral and theoretical profile of all three complexes 28 30. These results can be rationalized by the greater $\pi$ accepting
Table 5 Photophysical data for complexes 28-30 in degassed $\mathrm{CH}_{2} \mathrm{Cl}_{2}$ at $\mathrm{rt}$

\begin{tabular}{llccc}
\hline & $\lambda_{\text {max }}^{\mathrm{em}} / \mathrm{nm}$ & $\Phi$ & $k_{\mathrm{obs}} / \mathrm{s}^{-1}$ & $k_{\mathrm{r}} / \mathrm{s}^{-1}$ \\
\hline $\mathbf{2 8}$ & {$[485,521,563,617(\mathrm{sh})]^{a}$} & & {$\left[4.1 \times 10^{2}\right]^{a}$} \\
$\mathbf{2 9}$ & $571,[553]^{a}$ & 0.24 & $1.4 \times 10^{5}$ & $3.3 \times 10^{4}$ \\
$\mathbf{3 0}$ & $575,[556]$ & 0.18 & $1.2 \times 10^{5}$ & $2.1 \times 10^{4}$ \\
${ }^{a}$ Data in square brackets are measured in $\mathrm{CH}_{2} \mathrm{Cl}_{2}$ matrix at $77 \mathrm{~K}$.
\end{tabular}

property of $\mathrm{CO}$ than of $\mathrm{PPh}_{2} \mathrm{Me}$ and $\mathrm{PPhMe}_{2}$ ligands, such that complex 27 with dual CO ligands renders a much reduced electron density in the $\mathrm{d}_{\pi}$ orbital, giving a lesser amount of the MLCT contribution.

Theoretically, owing to the direct involvement of the metal $\mathrm{d} \pi$ orbital, a greater contribution of the MLCT should accordingly enhance the spin-orbit coupling and hence the mixing between singlet and triplet manifolds, resulting in the shortening of the phosphorescence radiative lifetime. In contrast, the greater proportion of $\pi \pi^{*}$ contribution in the $\mathrm{T}_{1}$ state of $\mathbf{2 8}$ produces an exceedingly long radiative lifetime. This, in combination with perhaps the increase of deactivating modes, gives rise to an essentially non-emissive property for $\mathbf{2 8}$ in the room temperature fluid state. We expect that this knowledge should be of importance in improving the phosphorescent quantum efficiency of all heavy transition metal complexes.

\subsection{Ru-pyridyl azolate complexes suited for solar energy harvesting}

The pyridyl azolate ligand has been found useful for giving new designs that allow preparation of solar cell sensitizers with increased optical extinction coefficients. Thus, $\mathrm{Ru}(\mathrm{II})$ based complexes 31 and 32 were synthesized using the multi-step protocol developed by Grätzel and co-workers. ${ }^{29}$ It involves the prior treatment of tridenate (fpbpy) $\mathrm{H}$ with ruthenium reagent $\left[\mathrm{RuCl}_{2}(p \text {-cymene })_{2}\right]$ at $60^{\circ} \mathrm{C}$ in $\mathrm{DMF}$, followed by addition of bipyridine or the respective 4,4'-dicarboxy2,2'-bipyridine at $150^{\circ} \mathrm{C}$ to afford the $\mathrm{Cl}$-substituted intermediates. Subsequent replacement of chloride with thiocyanate gave the anticipated $\mathrm{N}$-coordinated thiocyanate complexes $\mathbf{3 1}$ and 32 in moderate yields. ${ }^{30}$ The X-ray structural analysis on model complex 31 revealed the hexacoordinated Ru(II) metal center encapsulated with one tridentate fpbpy ligand, one bipyridine, and one N-bound thiocyanate ligand, which served as the unambiguous identification of this new class of solar sensitizers.
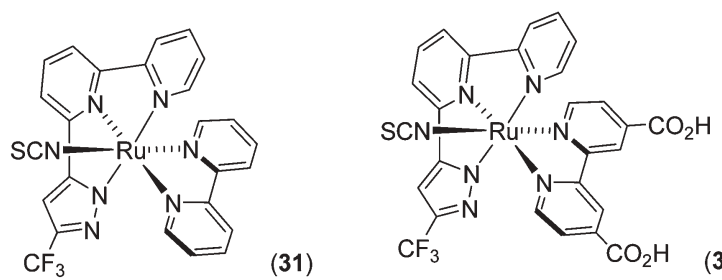

For the dicarboxy functionalized adduct 32, our spectral data showed that it possesses a larger adsorptivity of $2.4 \times$ $10^{-7} \mathrm{~mol} \mathrm{~cm}{ }^{-2}$ on nanocrystalline $\mathrm{TiO}_{2}$ thin film, in comparison to that of the commercially available $\mathrm{N} 3$ dye 
$\left(1.1 \times 10^{-7} \mathrm{~mol} \mathrm{~cm}^{-2}\right)$. The solar cells were then fabricated using 32 and optimized to achieve the best performances. It is notable that, under the standard AM 1.5 irradiation, the maximum incident photon-to-current conversion efficiency (IPCE) for the 32-sensitized $\mathrm{TiO}_{2}$ solar cell $\left(0.5 \times 0.4 \mathrm{~cm}^{2}\right)$ was calculated to be $5.53 \%$, with a short-circuit current $\left(J_{\mathrm{sc}}\right)$ of $13.0 \mathrm{~mA} \mathrm{~cm}{ }^{-2}$, an open-circuit photovoltage $\left(V_{\mathrm{oc}}\right)$ of $0.63 \mathrm{~V}$, and a fill factor $(F F)$ of 0.61 . For comparison, the similarly prepared, N3-sensitized solar cell gave a marginally better IPCE of $6.09 \%$, a $J_{\text {sc }}$ of $14.3 \mathrm{~mA} \mathrm{~cm} \mathrm{~cm}^{-2}$, a $V_{\text {oc }}$ of $0.69 \mathrm{~V}$, and a comparable $F F$ of 0.62 . Based on this finding, we are confident that the related fpbpy chelate or its functionalized analogues should be valuable in improving the basic design of $\mathrm{Ru}(\mathrm{II})$ sensitizers documented in the current literature.

\section{Complexes with $\mathrm{Os}(\mathrm{CO})_{3} \mathrm{X}$ unit}

\subsection{Diketonate complexes}

Photophysical studies of lower oxidation state rhenium complexes with structural formula $f a c-\left[\operatorname{Re}(\mathrm{CO})_{3} \mathrm{X}(\mathrm{L})\right], \mathrm{X}=$ halides and $\mathrm{L}=$ bidentate heterocycles such as $2,2^{\prime}$-bipyridine, have received considerable attention during the past two decades. $^{31}$ The observed emission could originate from the ligand centred $\pi \pi^{*}$, LLCT, or even MLCT states, depending on the nature of heterocyclic ligands. Moreover, the central metal cation would also have a notable influence on their photophysical properties. This gives us the motivation to initiate the studies of the heretofore unexplored isoelectronic Os(II) analogues.

Accordingly, a series of $\beta$-diketonate complexes with formula $\left[\mathrm{Os}(\mathrm{CO})_{3}(\mathrm{tfa})(\mathrm{LX})\right](33-39)$ were synthesized from the osmium dimer $\left[\mathrm{Os}_{2}(\mathrm{CO})_{6}(\mathrm{tfa})_{2}\right](\mathrm{tfa}=$ trifluoroacetate $)$ with the respective diketone reagent $(\mathrm{LX}) \mathrm{H}$ in a Carius tube. ${ }^{32}$

$$
\mathrm{Os}_{2}(\mathrm{CO})_{6}(\mathrm{tfa})_{2}+(\mathrm{LX}) \mathrm{H} \rightarrow\left[\mathrm{Os}(\mathrm{CO})_{3}(\mathrm{tfa})(\mathrm{LX})\right]+\mathrm{H}_{2}
$$

The structures of these complexes and their remarkable variation in photophysical properties are summarized in Scheme 4. For the hfac complex 33, a strong emission appeared at $\lambda_{\max }=545 \mathrm{~nm}$. Its phosphorescent character is ascertained by its large Stokes shift $v s$ its lowest energy absorption and long radiative lifetime, $\tau_{\mathrm{r}}$, of $\sim 7 \mu$ s calculated by $\tau_{\mathrm{r}}=\tau_{\mathrm{p}} / \Phi\left(\tau_{\mathrm{p}}\right.$ : observed decay time, $\Phi$ : emission yield $)$. Upon replacing one $\mathrm{CF}_{3}$ substituent with the phenyl group, forming

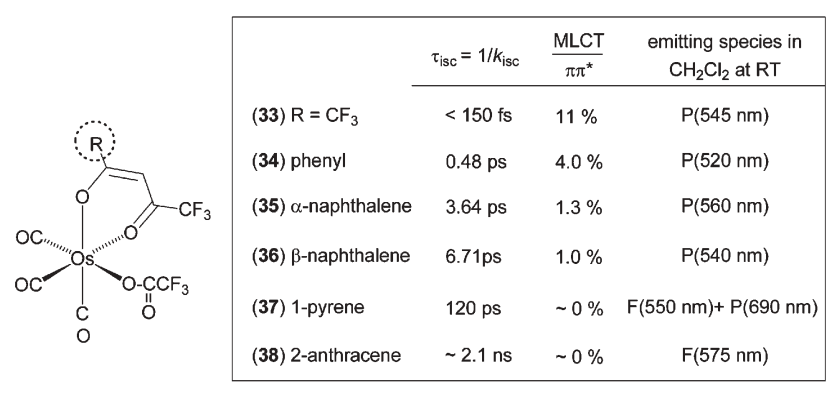

F: fluorescence, P: phosphorescence

Scheme 4 complex 34, the emission is still dominated by phosphorescence, as indicated by its drastic $\mathrm{O}_{2}$ quenching effect.

Replacing the aromatic pendant with either $\alpha$ or $\beta$-naphthalene, forming 35 and $\mathbf{3 6}$, respectively, also gives rise to unique phosphorescence with peak wavelengths at 560 and $540 \mathrm{~nm}$, respectively. However, in contrast to the sole phosphorescence for complexes 33-34 in both degassed and aerated $\mathrm{CH}_{2} \mathrm{Cl}_{2}$, dual emission consisting of fluorescence and phosphorescence was resolved for $\mathbf{3 5}$ and $\mathbf{3 6}$ under aerated conditions, indicating their reduced $\mathrm{S}_{1}-\mathrm{T}_{1}$ intersystem crossing rate, $k_{\mathrm{isc}}$. Further substitution of pyrene (37) reveals drastically different excitation behavior. This is confirmed by the observation of dual fluorescence $(550 \mathrm{~nm})$ and phosphorescence $(690 \mathrm{~nm})$ with a $\sim 1: 1.2$ intensity ratio. In contrast, complex 38 exhibits only fluorescence, regardless of whether it is in degassed or aerated solution, as supported by the excessive short radiative lifetime of $2.1 \mathrm{~ns}$. Nevertheless, weak phosphorescence with a peak wavelength at $\sim 740 \mathrm{~nm}$ was resolved for $\mathbf{3 8}$ in a $77 \mathrm{~K}$ methylcyclohexane glass matrix.

The changes in the lowest energy excited state character can be rationalized by the $\pi$ conjugation introduced by the polyaromatic pendant at the diketonate, reducing the energy gap between the $\pi$ and $\pi^{*}$-orbital of the $S_{1}$ and $T_{1}$ states in a qualitative manner. Moreover, the fast $k_{\text {isc }}$ observed in $\mathbf{3 3}$ and 34 can be rationalized by mixed MLCT and $\pi \pi^{*}$ in character in both $\mathrm{S}_{1}$ and $\mathrm{T}_{1}$ manifolds. If intersystem crossing takes place mainly from the $S_{1} \rightarrow T_{1}$ pathway, the corresponding rate constant, $k_{\text {isc }}$, is proportional to the equation

$$
\frac{\left\langle T_{1}\left|H_{\mathrm{so}}\right| \mathrm{S}_{1}\right\rangle^{2}}{\left(\Delta E_{\mathrm{S}_{1}-\mathrm{T}_{1}}\right)^{2}}
$$

where $H_{\mathrm{so}}$ is the Hamiltonian for the spin-orbit coupling, and $\Delta E_{\mathrm{S} 1-\mathrm{T} 1}$ is the energy difference between singlet $\left(\mathrm{S}_{1}\right)$ and triplet $\left(\mathrm{T}_{1}\right)$ states. Mixing of $\pi \pi^{*}$ and MLCT in both $\mathrm{S}_{1}$ and $\mathrm{T}_{1}$ states leads to the $\mathrm{S}_{1} \rightarrow \mathrm{T}_{1}$ intersystem crossing incorporating $\left\langle{ }^{1} \mathrm{~d}_{\pi} \pi^{*}\left|H_{\mathrm{so}}\right|^{3} \pi \pi^{*}\right\rangle$ or $\left\langle{ }^{3} \mathrm{~d}_{\pi} \pi^{*}\left|H_{\mathrm{so}}\right|^{1} \pi \pi^{*}\right\rangle$ term. The net result induces the change of orbital angular momentum, i.e. $\mathrm{d}_{\pi} \rightarrow \pi$ coupled with the flip of the electron spin, such that the transition has a significantly large first-order spin-orbit coupling term, resulting in an enhancement of the intersystem crossing. ${ }^{33}$

Accordingly, as revealed in Scheme 4, the greatest MLCT/ $\pi \pi^{*}$ mixing in $\mathbf{3 3}$ and $\mathbf{3 4}$ gives rise to ultrafast, system-response $\left(>10^{13} \mathrm{~s}^{-1}\right.$ ) limited $k_{\text {isc }}$. As for the lack of MLCT/ $\pi \pi^{*}$ state mixing in $37, k_{\text {isc }}$ decreases drastically to $9.2 \times 10^{9} \mathrm{~s}^{-1}$. Apparently, due to the lack of MLCT, complexes $\mathbf{3 7}$ and $\mathbf{3 8}$ mainly undergo a ${ }^{1} \pi \pi^{*} \rightarrow{ }^{3} \pi \pi^{*}$ intersystem crossing, in which the coupling between orbital and spin angular momentum and hence $\left\langle{ }^{1} \pi \pi^{*}\left|H_{\mathrm{so}}\right|^{3} \pi \pi^{*}\right\rangle$ should be rather small due to negligible changes of orbital angular momentum that can couple with the flip of electron spin. In other words, there is small first-order spinorbit coupling to enhance the intersystem crossing.

The unique room-temperature fluorescence observed in $\mathbf{3 8}$ is due to its much smaller $k_{\text {isc }}\left(\tau_{\text {isc }}=1 / k_{\text {isc }}>2.1 \mathrm{~ns}\right.$, see Scheme 4$)$. With the same $\pi \pi^{*}$ character dominating in the lowest lying singlet and triplet manifolds of $\mathbf{3 7}$ and $\mathbf{3 8}$, the distance $r$ of spin-orbit coupling, which is implicitly expressed in $H_{\mathrm{so}}$, becomes critical in manifesting $k_{\text {isc }}$. Working from an oversimplified approach, assuming Os(II) atom to be hydrogen-like, $k_{\text {isc }}$ is inversely proportional to $r^{6,34}$ in which $r$ is 


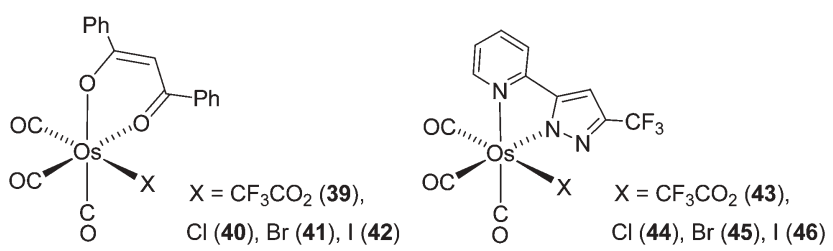

Scheme 5

taken as the distance from osmium atom to the gravitation center of the aromatic pendants and calculated to be 6.17 and $7.89 \AA$ for 37 and 38, respectively. Consequently, the ratio of $k_{\text {isc }}$ is calculated to be $1(37): 0.27(38)$, which is qualitatively in agreement with the experimental results of $1: 0.06$, taking into account that $r$ is ill-defined and the $r^{6}$ relationship is oversimplified.

To investigate the effect of the anionic ligands $\mathrm{X}$ in this class of Os(II) complexes, we also conducted the preparation of dibenzoylmethanate complexes using similar methods. ${ }^{35}$ Their structures are depicted in Scheme 5, while Table 6 shows their photophysical data. Their emissions occur in the region of $c a$. $538-574 \mathrm{~nm}$ and the lifetimes are relatively longer, giving characteristics of the $\pi \pi^{*}$ phosphorescence with high quantum yields of $0.08-0.13$. The only one showing distinctive behavior is the iodide complex $42(\Phi=0.007)$, which may be caused by the photoinduced Os-I bond scission, as indicated by the significant decrease of phosphorescence upon prolonged photolysis. The hypsochromic shift of the emission peak maximum followed the order of $\mathrm{tfa}>\mathrm{Cl}>\mathrm{Br}>\mathrm{I}$, which is related to the $\pi$-donor strength of anion that destabilizes the metal $\mathrm{d}_{\pi}$ orbital, hence increasing the MLCT contribution and decreasing the energy gap.

Recently, we have extended this series of investigation to the pyridyl pyrazolate derivatives $\mathbf{4 3}-\mathbf{4 6}$. They exhibited novel blue phosphorescence in the range 435-486 $\mathrm{nm}$, and the emission quantum yields were found to be lowered upon switching from tfa ligand (43: $\Phi=0.26)$ to halide ions (44: $\Phi=0.05,45: \Phi=$ $\left.0.003,46: \Phi=<10^{-4}\right)$. It is notable that their radiative lifetimes remain approximately the same, but the non-radiative rate constant were found to increase in the order $\mathrm{I}>\mathrm{Br}>\mathrm{Cl}$ $>$ tfa. Again, this tendency showed good correlation with the result of DFT calculation, for which a steady decrease of the gap between the lowest lying excited state $\left(T_{1}\right)$ and the higher energy states $\left(\geqslant \mathrm{T}_{2}\right)$ that possess a greater amount of $\mathrm{MC} \mathrm{dd}$

Table 6 Photophysical properties of complexes 39-46 in fluid states at $\mathrm{rt}$

\begin{tabular}{lllll}
\hline & $\lambda_{\text {max }}^{\mathrm{em}} / \mathrm{nm}^{a}$ & $\tau_{\mathrm{obs}} / \mu \mathrm{s}^{a}$ & $\Phi_{\mathrm{em}}$ & $k_{\mathrm{r}} / 10^{3} \mathrm{~s}^{-1 b}$ \\
\hline $\mathbf{3 9}$ & $538(541)$ & 64 & 0.13 & 2.02 \\
$\mathbf{4 0}$ & $557(537)$ & 46 & 0.13 & 2.76 \\
$\mathbf{4 1}$ & $563(561)$ & 29 & 0.08 & 2.82 \\
$\mathbf{4 2}$ & $574(602)$ & $0.72,38^{c}$ & $7 \times 10^{-3}$ & 0.18 \\
$\mathbf{4 3}$ & $435,460,486$ & 143 & 0.26 & 1.82 \\
$\mathbf{4 4}$ & $432,457,480$ & 25.6 & 0.05 & 1.95 \\
$\mathbf{4 5}$ & $431,458,484$ & 2.07 & $3 \times 10^{-3}$ & 1.45 \\
$\mathbf{4 6}$ & $435,457,479$ & $<3 \times 10^{-4}$ & $<10^{-4}$ &
\end{tabular}

${ }^{a}$ Data of 39-42 and 43-46 were measured in $\mathrm{CH}_{2} \mathrm{Cl}_{2}$ and acetonitrile employing $380 \mathrm{~nm}$ and $315 \mathrm{~nm}$ excitation, respectively. ${ }^{b} k_{\mathrm{r}}=\Phi_{\mathrm{em}} / \tau$. ${ }^{c}$ This sample showed biexponential decay behavior. character, were observed. As a result, thermal population to these vicinal higher lying excited states would unavoidably trigger the rapid radiationless deactivation.

\subsection{Quinolinolate complexes}

Syntheses of the Os(II) quinolinolate complexes are motivated by the consideration that $\mathrm{Al}$ (III) quinolinolate and its homologues were extensively tested for application as the emitting or the electron transporting materials in OLEDs.

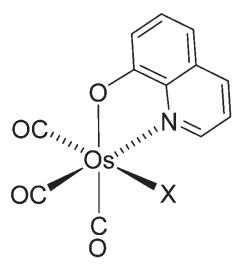

(47) $\mathrm{X}=\mathrm{CF}_{3} \mathrm{CO}_{2}$

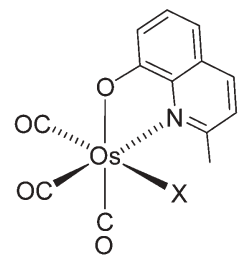

(49) $\mathrm{X}=\mathrm{CF}_{3} \mathrm{CO}_{2}$

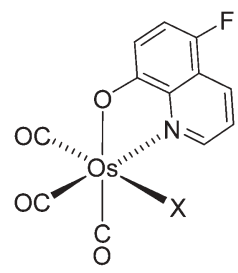

(50) $\mathrm{X}=\mathrm{CF}_{3} \mathrm{CO}_{2}$
(48) $X=1$

Remarkably, they have exhibited good illustration of the structural modifications that imposed the basic photophysical properties. ${ }^{36}$ The room-temperature absorption and emission spectra of complexes $\mathbf{4 7 - 5 0}$ in toluene are shown in Fig. 3. The lower lying absorption peak located near $420-450 \mathrm{~nm}$ is derived from a $\pi \pi^{*}$ transition with a significant contribution from the ILCT transition. ${ }^{37}$ This delineation shows good agreement with the $\sim 20 \mathrm{~nm}$ bathochromic shift of a similar absorption band of $\mathbf{5 0}$, for which fluorine substitution at the 5 -position is expected to markedly lower the $\pi \pi$ energy gap of the quinolinolate fragment because of the resonance (i.e., mesomeric) effect. The assignment to the MLCT band is discarded due to the lack of electronic dependence on the metal environment in the iodide complex $\mathbf{4 8}$.

As depicted in Fig. 3, except for the fluorine-substituted complex 50, in which only fluorescence could be resolved, complexes 47-49 revealed two distinct bands, which varied according to the quinolinolate ligands and the anionic ancillary ligands. The shorter-wavelength band, showing

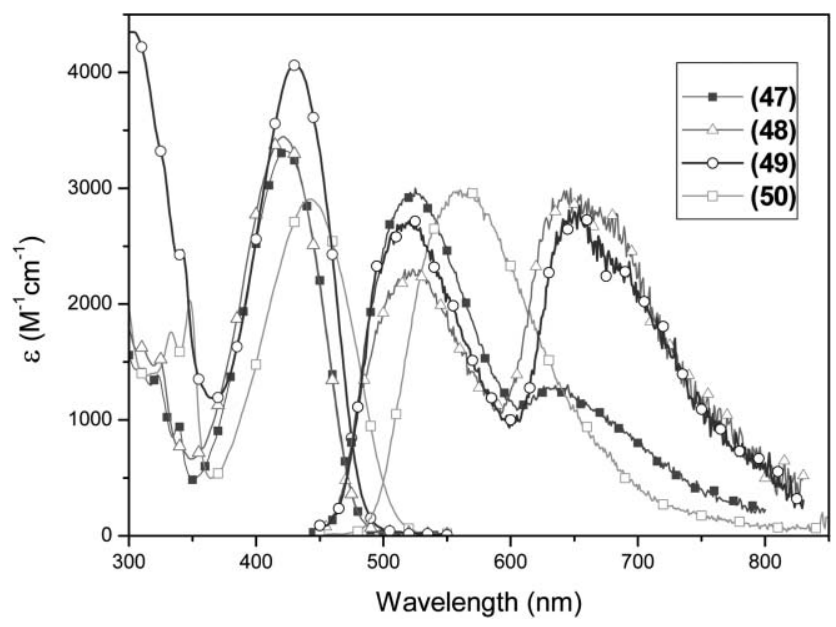

Fig. 3 UV-Vis absorption and normalized emission spectra of $\mathbf{4 7}$ (- - -), $48(-\Delta-), \mathbf{4 9}(-\bigcirc-)$ and 50 (- $\square-)$ in toluene at rt. 
characteristics of a short lifetime $(<<2 \mathrm{~ns})$, is classified as fluorescence, while the longer wavelength band can be assigned to the phosphorescence on the basis of its longer lifetime $(>1 \mu \mathrm{s})$ and drastic quenching effect under oxygen. It is believed that both of these emissions are dominated by $\pi \pi^{*}$ transition in combination with some amount of ILCT character, the latter, in part, incorporates the transfer of electron densities from the oxygen atom of the phenolate fragment to the $\pi^{*}$ orbitals of the fused ring system.

The variation in the intensity ratio of dual emissions, i.e. fluorescence vs phosphorescence, can be correlated with the relaxation dynamics of the $S_{1} \rightarrow T_{1}$ intersystem crossing. Relative to 47 , the addition of a 2 -methyl group in 49 which gives a threefold enhancement of $k_{\text {isc }}$ may be rationalized by the increase of density of the final vibronic states $\left(\mathrm{T}_{1}\right)$ having the same energy as the initial states $\left(\mathrm{S}_{1}\right)$. For $\mathbf{5 0}$, the mesomeric effect introduced by the fluoro substituent at the quinolinolate would result in the retardation of intersystem crossing and hence give a reduction of $k_{\text {isc }}$. However, in the case of iodidesubstituted 48, the phosphorescence was significantly increased, plausibly due to an additional iodide heavy atom effect that drastically increased the rate of intersystem crossing (vide infra).

\section{Conclusions}

To sum up, in this tutorial review, we discuss the chemistry of C-linked pyridyl azolate chromophores and present several prototypical designs that allow subtle variation of their fundamental properties. We then demonstrate the power of these chromophores and (azolate-3-yl)-2,2'-bipyridine, acting as bidentate and tridentate, respectively, to build up the target complexes. Particular attention is drawn to the reaction mechanism, such that readers can gain insight into the synthetic chemistry. The facile functionalization of these chromophores, together with strategic designs on the other ancillary ligands and their relative orientation, makes the corresponding neutral Os(II) and Ru(II) complexes versatile for latent applications.

The subtlety of the ligand orientation is illustrated via strongly luminescent 7 versus nearly non-luminescent $8 .^{17}$ This result should spark a broad interest in that the trans-effect may play a key role to induce distinctive photophysical behavior. As for axial-ligand luminescence tuning, an elegant example is demonstrated using complexes 9-13. ${ }^{20}$ The results lead to a prospect that coarse tuning can be achieved by altering the electron donating-withdrawing properties of the axial N-heterocyclic ligand, while fine-tuning may be manipulated by the substituent on the pyridyl azolates. Thus, the design and applications toward multiple hues are feasible and versatile.

In view of the tutorial intent of this review, it is important to emphasize the importance of the basic luminescent properties. Accordingly, we present a series of related Os(II) complexes possessing $\beta$-diketonates $^{32}$ and quinolinates ${ }^{36}$ to demonstrate the orbital origin as well as spin-orbit coupling distance dependent mixing efficiency between $S_{1}$ and $T_{1}$ and hence the rate of $\mathrm{S}_{1} \rightarrow \mathrm{T}_{1}$ intersystem crossing $\left(k_{\text {isc }}\right)$. Note that due to the spin-borrowing effect, i.e. triplet mixing with a singlet character, the results also influence the $T_{1} \rightarrow S_{0}$ radiative decay rate.

We then formulate a semi-empirical approach regarding how to access the magnitude of spin-orbit coupling. Knowing that metal $d_{\pi}$ orbital is directly coupled into the spin-orbit coupling matrix, the rate of $S_{1} \rightarrow T_{1}$ intersystem crossing as well as the $T_{1} \rightarrow S_{0}$ radiative decay rate should be dominated by the participation of MLCT character. Consequently, with a lesser contribution of MLCT (e.g. $<10 \%)$, mixing between MLCT and ILCT (or LLCT), i.e. the degree of

$$
\left\langle\mathrm{d}_{\pi} \pi^{*}\left|H_{\mathrm{so}}\right|^{1} \pi \pi^{*}\right\rangle
$$

or

$$
\left\langle\mathrm{d}_{\pi} \pi^{*}\left|H_{\mathrm{so}}\right|^{3} \pi \pi^{*}\right\rangle
$$

coupling may become a key factor to facilitate the population efficiency as well as the corresponding phosphorescence radiative decay rate. As a result, the intersystem crossing rate can be qualitatively predicted via the theoretical analyses. If the target complexes possess pure $\pi \pi^{*}$ character in both lowest lying singlet and triplet manifolds, the distance $(r)$ between ligand chromophore and metal center becomes increasingly important due to the empirical $r^{6}$ dependence for the heavy atom effect ( $c f .37$ and 38). ${ }^{32}$ Finally, particular attention is required to avoid $\mathrm{MC} \mathrm{dd}$ participation in the lower lying transition if the goal is to achieve decent phosphorescent efficiency. As for the case of neutral redemitting Ru(II) complexes, we believe that the ligand design for averting the $\mathrm{MC}$ dd character into the lowest triplet state plays a key role in improving the luminescent behavior. ${ }^{25}$ Such a strategy should be equally valid to other systems incorporating both second and third-row transition metal elements. We thus hope that the chemistry and photophysics of the neutral Os(II) and Ru(II) complexes presented in this tutorial review will provide timely feedback for the reader to pursue rational design of luminescent transition metal complexes not only suited for OLEDs but also extending toward territories such as imaging, optical communication and photovoltaic systems, etc.

\section{Acknowledgements}

We are grateful for the financial support from the National Science Council and the Ministry of Economic Affairs.

\section{References}

1 E. Baranoff, J.-P. Collin, L. Flamigni and J.-P. Sauvage, Chem. Soc. Rev., 2004, 33, 147.

2 P.-T. Chou and Y. Chi, Eur. J. Inorg. Chem., 2006, 3319.

3 R. C. Evans, P. Douglas and C. J. Winscom, Coord. Chem. Rev., 2006, 250, 2093.

4 Y. Kawamura, K. Goushi, J. Brooks, J. J. Brown, H. Sasabe and C. Adachi, Appl. Phys. Lett., 2005, 86, 071104.

5 M. S. Lowry and S. Bernhard, Chem.-Eur. J., 2006, 12, 7970.

6 J. Slinker, D. Bernards, P. L. Houston, H. D. Abruna, S. Bernhard and G. G. Malliaras, Chem. Commun., 2003, 2392.

7 S. Welter, K. Brunner, J. W. Hofstraat and L. De Cola, Nature, 2003, 421, 54.

8 B. Carlson, G. D. Phelan, W. Kaminsky, L. Dalton, X. Z. Jiang, S. Liu and A. K.-Y. Jen, J. Am. Chem. Soc., 2002, 124, 14162.

9 S. P. Singh, D. Kumar, B. G. Jones and M. D. Threadgill, J. Fluorine Chem., 1999, 94, 199. 
10 A. Satake and T. Nakata, J. Am. Chem. Soc., 1998, 120, 10391.

11 J. G. Vos and J. M. Kelly, Dalton Trans., 2006, 4869.

12 K. Funabiki, N. Noma, G. Kuzuya, M. Matsui and K. Shibata, J. Chem. Res. (M), 1999, 1301.

13 R. Hage, R. Prins, J. G. Haasnoot, J. Reedijk and J. G. Vos, J. Chem. Soc., Dalton Trans., 1987, 1387.

14 P.-C. Wu, J.-K. Yu, Y.-H. Song, Y. Chi, P.-T. Chou, S.-M. Peng and G.-H. Lee, Organometallics, 2003, 22, 4938.

15 F.-C. Hsu, Y.-L. Tung, Y. Chi, C.-C. Hsu, Y.-M. Cheng, M.-L. Ho, P.-T. Chou, S.-M. Peng and A. J. Carty, Inorg. Chem., 2006, 45, 10188 .

16 M.-D. Su, H.-Y. Liao, S.-Y. Chu, Y. Chi, C.-S. Liu, F.-J. Lee, S.-M. Peng and G.-H. Lee, Organometallics, 2000, 19, 5400.

17 J.-K. Yu, Y.-H. Hu, Y.-M. Cheng, P.-T. Chou, S.-M. Peng, G.-H. Lee, A. J. Carty, Y.-L. Tung, S.-W. Lee, Y. Chi and C.-S. Liu, Chem.-Eur. J., 2004, 10, 6255.

18 N. J. Turro, Modern Molecular Photochemistry, University Science Books, Mill Valley, California, 1991, ch. 6, p. 170.

19 A. B. Tamayo, B. D. Alleyne, P. I. Djurovich, S. Lamansky, I. Tsyba, N. N. Ho, R. Bau and M. E. Thompson, J. Am. Chem. Soc., 2003, 125, 7377

20 S.-W. Li, Y.-M. Cheng, Y.-S. Yeh, C.-C. Hsu, P.-T. Chou, S.-M. Peng, G.-H. Lee, Y.-L. Tung, P.-C. Wu, Y. Chi, F.-I. Wu and C.-F. Shu, Chem.-Eur. J., 2005, 11, 6347.

21 Y.-L. Tung, P.-C. Wu, C.-S. Liu, Y. Chi, J.-K. Yu, Y.-H. Hu, P.-T. Chou, S.-M. Peng, G.-H. Lee, Y. Tao, A. J. Carty, C.-F. Shu and F.-I. Wu, Organometallics, 2004, 23, 3745.

22 Y.-L. Tung, S.-W. Lee, Y. Chi, Y.-T. Tao, C.-H. Chien, Y.-M. Cheng, P.-T. Chou, S.-M. Peng and C.-S. Liu, J. Mater. Chem., 2005, 15, 460.

23 P.-I. Shih, C.-F. Shu, Y.-L. Tung and Y. Chi, Appl. Phys. Lett., 2006, 88, 251110.
24 K. Chen, Y.-M. Cheng, Y. Chi, M.-L. Ho, C.-H. Lai, P.-T. Chou, S.-M. Peng and G.-H. Lee, Chem.-Asian J., 2007, 2, 155.

25 Y.-L. Tung, S.-W. Lee, Y. Chi, L.-S. Chen, C.-F. Shu, F.-I. Wu, A. J. Carty, P.-T. Chou, S.-M. Peng and G.-H. Lee, Adv. Mater., 2005, 17, 1059.

26 Y.-L. Tung, L.-S. Chen, Y. Chi, P.-T. Chou, Y.-M. Cheng, E. Y. Li, G.-H. Lee, C.-F. Shu, F.-I. Wu and A. J. Carty, Adv. Funct. Mater., 2006, 16, 1615.

27 J. M. Patrick, A. H. White, M. I. Bruce, M. J. Beatson, D. St. C. Black, G. B. Deacon and N. C. Thomas, J. Chem. Soc. Dalton Trans., 1983, 2121.

28 E. Y. Li, Y.-M. Cheng, C.-C. Hsu, P.-T. Chou, G.-H. Lee, I.-H. Lin, Y. Chi and C.-S. Liu, Inorg. Chem., 2006, 45, 8041

29 M. K. Nazeeruddin, S. M. Zakeeruddin, J.-J. Lagref, P. Liska, P. Comte, C. Barolo, G. Viscardi, K. Schenk and M. Grätzel, Coord. Chem. Rev., 2004, 248, 1317.

30 K.-S. Chen, W.-H. Liu, Y.-H. Wang, C.-H. Lai, P.-T. Chou, G.-H. Lee, K. Chen, H.-Y. Chen, Y. Chi and C.-F. Tung, $A d v$. Funct. Mater., 2007, DOI: 10:1002/adfm.200600985.

31 A. Vogler and H. Kunkely, Coord. Chem. Rev., 2000, 200-202, 991.

32 Y.-L. Chen, S.-W. Li, Y. Chi, Y.-M. Cheng, S.-C. Pu, Y.-S. Yeh and P.-T. Chou, ChemPhysChem, 2005, 6, 2012.

33 T. Yutaka, S. Obara, S. Ogawa, K. Nozaki, N. Ikeda, T. Ohno, Y. Ishii, K. Sakai and M. Haga, Inorg. Chem., 2005, 44, 4737.

34 S. P. McGlynn, T. Azumi and M. Kinoshita, Molecular Spectroscopy of the Triplet State, Prentice Hall, Inc., Englewood Cliffs, New Jersey, 1969. ch. 5, p. 189.

35 Y.-L. Chen, C. Sinha, I.-C. Chen, K.-L. Liu, Y. Chi, J.-K. Yu, P.-T. Chou and T.-H. Lu, Chem. Commun., 2003, 3046.

36 Y.-M. Cheng, Y.-S. Yeh, M.-L. Ho, P.-T. Chou, P.-S. Chen and Y. Chi, Inorg. Chem., 2005, 44, 4594.

37 R. Ballardini, G. Varani, M. T. Indelli and F. Scandola, Inorg. Chem., 1986, 25, 3858. 